Шадеко Василий Петрович, Несмеянов Алексей Владимирович

ОМОНИМЫ В СОВРЕМЕННОМ НЕМЕЦКОМ ЯЗЫКЕ: ПУТИ ВОЗНИКНОВЕНИЯ И

\title{
ТИПОЛОГИЧЕСКАЯ ХАРАКТЕРИСТИКА
}

В данной статье дается предельно сжатый и вместе с тем достаточно полный обзор такого явления немецкого языка, как омонимия: а) показаны пути возникновения омонимов (распад полисемии, переход слова из одной части речи в другую, возникновение омонимов в результате исторических изменений в фонетической системе немецкого языка, совпадение немецких слов и слов, заимствованных из других языков); б) указана дифференциация омонимов на лексические, грамматические и лексико-грамматические; в) дана десиниция полных и частичных омонимов; г) приведено противопоставление нейтральных и стилистически окрашенных омонимов; д) выявлены критерии разграничения омонимии и полисемии.

Адрес статьи: www.gramota.net/materials/2/2018/8-2/40.html

\section{Источник}

Филологические науки. Вопросы теории и практики

Тамбов: Грамота, 2018. № 8(86). Ч. 2. С. 398-402. ISSN 1997-2911.

Адрес журнала: www.gramota.net/editions/2.html

Содержание данного номера журнала: www.gramota.net/materials/2/2018/8-2/

\section{() Издательство "Грамота"}

Информация о возможности публикации статей в журнале размещена на Интернет сайте издательства: www.gramota.net Вопросы, связанные с публикациями научных материалов, редакция просит направлять на адрес: phil@gramota.net 
3. Кирилина А. В., Томская М. В. Лингвистические гендерные исследования // Отечественные записки. 2005. № 2 (23). C. $112-132$.

4. Колокольцева Т. Н. Специфические коммуникативные единицы диалогической речи. Волгоград: Изд-во Волгоградского ун-та, 2001. $260 \mathrm{c}$.

5. Argamon S., Koppel M., Fine J., Shimoni A. R. Gender, Genre, and Writing Style in Formal Written Texts // Text. 2003. Vol. 23. № 3. P. 321-346.

6. Brown P., Levinson S. C. Politeness: Some Universals in Language Usage. Cambridge: Cambridge University Press, 1987.358 p.

7. Chavez M. Gender in the Language Classroom. Boston: McGraw-Hill Education, 2000. 264 p.

8. Holmes J., Stubbe M. Power and Politeness in the Workplace: a Sociolinguistic Analysis of Talk at Work. L.: Routledge, 2015. $216 \mathrm{p}$.

9. Jones M. G., Wheatley J. Gender differences in teacher-student interactions in science classroom // Journal of Research in Science Teaching. 1990. Vol. 27. P. 861-874.

10. Michigan Corpus of Academic Spoken English (MICASE) [Электронный ресурc]. URL: https:/quod.lib.umich.edu/ cgi/c/corpus/corpus?page=home; $=$ micase; $c$ =micase (дата обращения: 01.02.2018).

11. Nelson Laird T. F., Garver A. K., Niskodé-Dossett A. S. Gender gaps in collegiate teaching style: Variations by course characteristics // Research in Higher Education. 2011. Vol. 52. Iss. 3. P. 261-277.

12. Römer U. Academic discourse, gender, and politeness [Электронный pecypc]. URL: http://www.nord.helsinki.fi/ clpg/CLPG/Ute\%20Romer.pdf (дата обращения: 26.02.2018).

13. Savicki V., Kelley M., Lingenfelter D. Gender, group composition and task type in small task groups using computer mediated communication // Computers in Human Behavior. Quebec, 1996. Vol. 2. P. 549-565.

14. Thimm C., Koch S. C., Schey S. Communicating gendered professional identity: Competence, cooperation, and conflict in the workplace // The Handbook of Language and Gender. Boston: Blackwell, 2003. P. 528-549.

\title{
GENDER ASPECT OF EXPRESSING DISAGREEMENT IN ORAL ACADEMIC DISCOURSE (BY THE MATERIAL OF THE MICASE CORPUS)
}

\author{
Khromenko Yana Vladimirovna \\ Saint Petersburg University \\ yanakhromenko@yandex.ru
}

The article analyzes the specificity of expressing disagreement from the viewpoint of the gender aspect by the example of Michigan Corpus of Academic Spoken English (MICASE). The author examines a communicative situation, in which the teacher corrects the student's mistake or disagrees with his opinion. The paper describes the basic means to explicate disagreement and pragmatic linguistic means to soften the categoricity of a statement in English scientific discourse. The analysis identified insignificant gender differences that testify for the necessity of the further verification of the stereotypes of male and female speech behaviour.

Key words and phrases: academic discourse; expressing disagreement; gender; corpus linguistics; linguistic corpus; Michigan Corpus of Academic Spoken English.

УДК 81

https://doi.org/10.30853/filnauki.2018-8-2.40

Дата поступления рукописи: 15.05.2018

В данной статье дается предельно сжатый и вместе с тем достаточно полный обзор такого явления немецкого языка, как омонимия: а) показаны пути возникновения омонимов (распад полисемии, переход слова из одной части речи в другую, возникновение омонимов в результате исторических изменений в фонетической системе немецкого языка, совпадение немецких слов и слов, заимствованных из других языков); б) указана дифференциация омонимов на лексические, грамматические и лексико-грамматические; в) дана дефиниция полных и частичных омонимов; г) приведено противопоставление нейтральных и стилистически окрашенных омонимов; д) выявлены критерии разграничения омонимии и полисемии.

Ключевые слова и фразы: значение; форма; омонимия; полисемия; омографы; омофоны; этимология; заимствование; субстантивация; конверсия.

Шадеко Василий Петрович, к. филол. н., доцент Несмеянов Алексей Владимирович, к. филол. н.

Ленинградский государственный университет имени А. С. Пушкина, г. Санкт-Петербург

v.shadeko@gmail.com;nesmejanow@mail.ru,a.nesmeyanov@lengu.ru

\section{ОМОНИМЫ В СОВРЕМЕННОМ НЕМЕЦКОМ ЯЗЫКЕ: ПУТИ ВОЗНИКНОВЕНИЯ И ТИПОЛОГИЧЕСКАЯ ХАРАКТЕРИСТИКА}

При изучении омонимии в любом языке возникает множество проблем, одной из которых является вопрос о причинах возникновения омонимов. Омонимии в целом и лексической омонимии в особенности посвящено огромное количество исследований, выполненных на разных языках, однако вопрос этот в лингвистике остается по-прежнему актуальным. Так, А. И. Головня в этой связи справедливо отметил, что «омонимия как проблема номер 1 - это: а) чисто теоретическая научная проблема языка и философии; б) прикладная проблема: автоматический перевод, автоматическое реферирование текстов, создание разного рода интеллектуальных 
систем; в) методическая проблема: обучение русскому как иностранному, разработка методических рекомендаций для составления словарей» [7]. Не удивительно поэтому, что преподаватели иностранных языков (и не только русского как иностранного; в нашем случае - немецкого языка в русской аудитории) еще и еще раз обращаются к этой проблеме. Приведенный в статье комплексный анализ внушительного массива конкретных немецких примеров и попытка систематизировать материал, выявив основные причины (пути) возникновения в языке омонимов, могут быть полезны не только в чисто теоретическом, но и в практическом плане для облегчения работы преподавателя и создания новых методических пособий и разработок, может быть, даже новых словарей. Актуальность настоящей работы пересекается, таким образом, с ее научной новизной и значимостью: свежий взгляд германистов, преподавателей-практиков на привычные лексические совпадения, еще одна попытка систематизации того, что систематизации в принципе поддается с трудом. Хотя именно такую цель мы поставили перед собой в настоящей статье и попытались ее достичь.

Термин «омоним» восходит к древнегреческим словам homos - ‘одинаковый’ и потеп - ‘имя'. Приведем несколько дефиниций понятий «омоним», «омонимы». «омонимия»: 1) «Две (или более) разные языковые единицы, совпадающие по звучанию (т.е. в плане выражения)» [3, с. 287]; 2) «Омонимы - это одинаково звучащие слова, но имеющие разное значение» [4, с. 170]; 3) «Традиционно омонимия - это звуковое совпадение двух или более языковых единиц» $[6$, с. 6]; 4) «Омонимы - это разные слова, имеющие одинаковый звуковой состав» [11, с. 90]; 5) "Homonyme sind Wörter mit gleichem Formativ und völlig unterschiedliher Bedeutung” [10, с. 21]. / «Омонимы - слова с одинаковой формой и с совершенно разным значением» (перевод автора статьи. - В. Ш.).

Видно, что все определения подчеркивают, что омонимы совпадают по форме, но различаются по своему значению. Таковы, например, в немецком языке: das Schloss - ‘зАмок’ и ‘замОк’; der Grund - 'причина' и 'дно'; die Bank - 'банк' и 'скамейка'; die Weise - 'путь, способ' и die Waise - 'сирота', stählen - ‘закалять' и stehlen 'красть, воровать', die Seite - ‘страница' и Saite - 'струна', der Laib - 'коврига' и der Leib - 'тело’ и т.д. Разное написание многих из этих слов имеет разные причины, которые связаны с путями их возникновения в языке.

Омонимы в немецком языке возникли разными путями. Первый путь связан с семантическим родством слов, т.е. омонимы появлялись на базе полисемии. Сначала существовало многозначное слово, а затем связи между лексико-семантическими вариантами разошлись. Таково в немецком языке der Schimmel - 'плесень' и der Schimmel - 'белая, серая лошадь', т.е. 'лошадь сивой масти'. Одна из новелл немецкого писателя второй половины XIX века Теодора Шторма так и называется “Der Schimmel”, что было переведено на русский язык как «Всадник на белом коне». Если мы сопоставим семантические признаки лексемы лошадь ('одушевленное, парнокопытное, белого цвета') и семантические признаки второй лексемы ('неодушевленное, вещество, простейшее, белого цвета'), то обнаружим одну общую сему - 'белый цвет’. Но поскольку белый цвет сегодня не соответствует этим денотатам, то семантическая связь между ними разрушилась.

Одна и та же лексема может иметь несколько омонимов, таковым в немецком языке является слово der Fuß: 1) 'ступня' (часть ноги); 2) ‘ножка' (стола или стула); 3) ‘фут’ (стопа как мера длины); 4) 'подножие’ (горы); 5) ‘основание’ (треугольника); 6) ‘стопа’ (в стихах); 7) ‘след’ (у чулка) и 8) ‘цоколь’ (в постройке). Такое семантическое разнообразие отражается и на грамматических формах: так, der Fuß ('нога’ и все прочие лексикосемантические варианты) - die Füßе, а вот если мы что-то измеряем, то говорим 20 Fuß lang (20 футов в длину).

Такая же семантическая дифференциация закрепилась в противопоставлении форм множественного числа омонимов die Bank ('банк') - (die Banken) ('банки’) и die Bank ('скамейка') - die Bänke ('скамейки'). Возможна дифференциация омонимов и по роду: der Band - 'том') и das Band - 'лента, тесьма'. Сначала в немецком языке была лексема das Band. Когда же изобрели книгопечатание и стали переплетать книги, то появилось и $d e r$ Band.

Таким образом, первый путь возникновения омонимов в немецком языке - это распад полисемии. Рассмотрим еще несколько примеров.

Связь между семантическими вариантами многозначного слова может прерваться, так как эти значения далеко разошлись, например, лексема der Stab первоначально имела значение 'палка', 'посох', затем появился лексико-семантический вариант 'жезл', а затем - 'символ власти'. Это значение сохранилось во фразеологизме den Stab brechen ('вынести окончательный приговор'); далее слово der Stab стало означать 'символ' командующего в армии, а затем уже в результате метонимического переноса с части на целое появился лексикосемантический вариант 'штаб'.

Те же самые метаморфозы произошли и с лексемой der Schild, обозначавшей ‘щит’ рыцаря, а затем его ‘эмблему' (das Schild), так как на щите обычно был обозначен герб рыцаря. В наши дни первый лексикосемантический вариант сохранился как историзм, а ко второму добавились еще значения 'бляха носильщика', 'этикетка, ярлык', ‘табличка с названием улицы, фамилии жильца' и т.п. Первая лексема имеет форму множественного числа die Schilde, а вторая - die Schilder. Или еще пример: der Stock - 'палка' и der Stock - 'этаж'. Раньше первый этаж строили из дерева, из которого состоит и палка. Здесь тоже налицо метонимический перенос названия материала на предмет изготовления. Различие существует лишь во множественном числе: die Stöcke - 'палки' и die Stockwerke - ‘этажи’.

Кроме распада полисемии, можно выделить чисто грамматический способ возникновения омонимов. Здесь следует говорить о переходе слова из одной части речи в другую, т.е. о конверсии. Так, например, существительное der Laut - 'звук' перешло в предлог laut - 'согласно, по', die Kraft - 'сила' - в kraft - 'в силу', ernst - 'серьезный' - в der Ernst - 'серьезность'.

Следует отметить, что большинство омонимов в современном немецком языке возникает благодаря субстантивации. Этот путь очень характерен именно для немецкого языка. Так, прилагательное jung ('молодой') 
перешло в существительное der Junge ('юноша'), глагол leben ('жить') - в das Leben ('жизнь'), глагол lachen ('смеяться') - в существительное das Lachen ('смех') и т.д. Грамматический способ возникновения омонимов в современном немецком языке можно условно обозначить как второй способ их появления в языке.

Третий путь возникновения омонимов - это исторические изменения в фонетической системе немецкого языка, имевшие место в прошлые века. Этот путь можно обозначить как путь случайных фонетических совпадений слов разного происхождения. В данном случае омонимия пересекается с этимологией. Так, германисты М. Д. Степанова и И. И. Чернышева отмечают, что в немецком языке значительное количество омонимов этого типа возникло в связи с тем, что в ранневерхненемецком периоде произошли качественные и количественные изменения гласных, что привело к совпадению фонемного состава, например, следующих средневерхненемецких форм: ср.в.н. töre $>$ der Tor - ср.в.н. tor $>$ das Tor; ср.в.н. wise $>$ die Weise - cp.в.н. weise $>$ die Waise; cp.в.н. site $>$ die Seite - cр.в.н. seite $>$ die Saite [12, с. 198]. В самом деле, семантической связи между лексемами das Tor - 'ворота' и der Tor - 'глупец’ не было, но в средневерхненемецкий период (с XI в. по XIV в.) было слово tor - 'ворота’ и tore - 'глупец'. Затем, в результате редукции безударных гласных, конечное -е пропало и обе лексемы стали иметь одинаковую форму. То же самое произошло и со словами die Hut (huote) 'охрана' и der Hut (huot) -'шляпа'. Кроме того, при переходе от средневерхненемецкого к ранневерхненемецкому периоду произошли качественные изменения и в области вокализма: дифтонгизация долгих гласных и монофтонгизация старых дифтонгов, в результате чего совпали die Saite (seite) - 'струна' и die Seite (site) 'сторона'. То же самое произошло с die Waise - 'сирота' и die Weise - 'способ, манера'.

Четвертый путь возникновения омонимов - это совпадение немецкого слова и слова, заимствованного из других языков. Так, было немецкое слово der Strauß - 'букет', и пришло в немецкий язык der Straus - 'страус'. Или лексема der Reis - 'рис' - тоже была заимствована. Латинское risus при переходе в немецкий язык дифтонгизировалось и совпало с общегерманским das Reis - 'вереск, хворост, ветка'. Пришедший из латинского языка глагол dictare - 'сочинять' превратился в немецком языке в dichten, где он совпал с немецким dichten 'сгущать'. Или немецкое слово der Ball - 'мяч' получило омоним, когда было заимствовано французское bal ‘бал, маскарад’, которое в немецком пишется как der Ball. Возможны случаи, когда оба омонима, существующие в современном немецком языке, являются заимствованными словами из разных языков. Таковы глаголы taktieren (лат. takt) - ‘отбивать такт’ и taktieren (греч. taktik) - ‘применять тактику'. Или der Star (лат. sturnus) 'скворец' и der Star (англ. star) - 'звезда'.

В результате всех этих процессов омонимы в современном немецком языке делятся на лексические, грамматические и лексико-грамматические.

Лексические омонимы - это слова, совпадающие по звучанию всех своих словоформ, например: die Mähre - ‘кляча' и 'известие'; der Stab - ‘посох, палка' и ‘военный штаб'; der Stock - 'этаж’ и 'палка'. Обычно такие омонимы называют полными. Как видно по примерам, это слова, которые являются омонимами в пределах одной и той же части речи.

Грамматические омонимы - это лексемы, совпадающие по своей грамматической форме, таковы в немецком языке существительные женского и среднего родов в именительном и винительном падежах (die Frau и das Kind); конъюнктив и индикатив в презенсе в примерах wir schreiben ('мы пишем') и sie schreiben ('они пишут').

Лексико-грамматические омонимы - это слова, которые относятся к разным частям речи, например, существительное der Laut - 'звук', наречие laut - 'громко' и предлог laut - 'согласно'; kraft - 'в силу' - die Kraft - 'сила'; прилагательное alte - 'старая' и существительное die Alte - 'старуха'; глагол kosten - 'стоить' и существительное die Kosten - ‘стоимость'; da - 'тут' - наречие и $d a$ - 'так как' - союз; ит - 'вокруг’ предлог и ит - 'чтобы' - союз.

Часто такие омонимы возникают при субстантивации прилагательных и наречий, cp.: fett - ‘жирный’ и das Fett - 'жир'. Может иметь место и обратный процесс - адъективация существительного, например: der Ernst 'серьезность' и еrnst - 'серьезный'. Лексико-грамматические омонимы - это слова, одинаково звучащие, но разные не только по значению, но и по своим грамматическим свойствам. Это могут быть имена существительные разного рода: der Band - 'том' и das Band - 'лента'; der Leiter - 'руководитель' и die Leiter - 'лестница'; der Kiefer - 'челюсть' и die Kiefer - 'сосна'; der Moment - 'мгновение' и das Moment - 'обстоятельство', $\operatorname{der} \mathrm{See}$ - 'озеро' и die See - 'море' и т.д. Омонимы-существительные, по-разному образующие форму множественного числа в современном немецком языке, чаще всего представляют собой омонимические пары: die Tücher - 'платки' и die Tuche - ‘сукна'; die Räte - 'советы', т.е. ‘органы власти' и die Ratschläge - 'советы', т.е. 'рекомендации'. Гораздо реже встречаются соответствующие триады: die Messe - ‘месса', 'ярмарка', ‘каюткомпания'; die Kapelle - ‘капелла', 'часовня', 'тигель (в технике)'.

Есть группа омонимов, которые совпадают во всех формах, имеют ту же парадигму склонения (полные омонимы). Это типично, в частности, для субстантивированных прилагательных, например: kranke Schwester 'больная сестра' и die Kranke - 'больная', dank - 'благодаря' и der Dank - 'благодарность', предлог sondern ‘а, но' и глагол sondern - 'сортировать'.

Встречаются и частичные омонимы, которые совпадают не во всех своих формах: существительное die Wüste - 'пустыня' и глагол wüste - 'знал бы', существительное die Braue - ‘бровь' и глагол braue - 'варю пиво', существительное die Fliege - 'муха' и fliege - ‘летаю', der Tor - 'глупец’ и die Toren - 'глупцы', das Tor - 'ворота' единственного числа и die Tore - ‘ворота' множественного числа, wiegen - ‘качать, баюкать' и wiegen 'взвешивать' wog, gewogen. 
Следует отметить, что омонимами могут оказаться стилистически нейтральные и стилистически окрашенные слова, ср.: der Koks - 'уголь' - нейтральное, der Koks - 'кокаин' и der Koks - 'чепуха' - разговорные. В отношения омонимии вступают общелитературные слова и жаргонизмы, например: puтреn - 'качать' нейтральное и pumpen - 'брать взаймы' - жаргонизм. Или слово заимствованное и вошедшее в литературную норму: die Pose - ‘поза' (из франц.) и die Pose (диалектизм) - 'поплавок’. Омонимы в немецком языке встречаются также среди архаизмов и неологизмов: архаизм das Fiat - 'разрешение' и неологизм der Fiat 'автомобиль марки «Фиат»'.

Как уже было отмечено, омонимия сопряжена с таким понятием, как «полисемия». Так, немецкое существительное das Glas многозначно. Прежде всего, оно обозначает вещество и ряд предметов из стекла ('рюмка', 'стакан', 'банка'), а также является компонентом, например, сложного слова das Opernglas - 'театральный бинокль', а форма множественного числа die Gläser обозначает 'очки'. Общим для всех вышеназванных слов является материал, из которого все эти вещи сделаны. Первоначальное слово das Glas и означало 'материал' ('стекло'), а затем по ассоциации в результате метонимического переноса возникли другие обозначения предметов из стекла.

Следует отметить, что многозначность заложена в самой природе слова. В немецком языке большинство слов многозначны, а однозначны, как правило, термины, и то далеко не всегда. Эту мысль подтверждает, например, то, что в толковых словарях братьев Гримм [14] Р. Клаппенбах и В. Штейница [16] словарные статьи на глагол тасhen занимают несколько страниц.

Снятию многозначности лексемы способствует контекст. Об этом писали многие лингвисты, особенно подробно рассматривает этот вопрос С. Д. Кацнельсон [8, с. 51]. Но иногда и контекст не снимает многозначности. Это происходит обычно при абстрактном значении слова, например, Alle bewundern sein Werk, где Werk обозначает отдельное произведение писателя или все его творчество. В данном случае требуется более широкий контекст. В слове заложена потенциальная возможность, которая и проявляется в речи. Именно в речи каждый раз актуализируется одно из значений слова.

Многозначность, или полисемия, тесно связаны с практической деятельностью людей, что представляет собой одно из неотъемлемых свойств языка. Интересно писал об этом Р. А. Будагов: «Лишенное многозначности слово перестало бы служить цивилизации. Оно было бы не в состоянии передать движение и развитие человеческой мысли. Непомерно разросшийся словарь языка вместе с тем состоял бы из слов слишком прямолинейных и недостаточно гибких для выражения всей сложности мыслей и чувств человека. Количество не может заменить качества» [4, с. 122]. Как бы ни было многозначно слово, среди его разнообразных значений всегда имеется центральное, или основное, цементирующее остальные значения в определенную эпоху жизни языка.

Возвращаясь к вопросу о сопряженности омонимии и полисемии, следует отметить, что очень часто бывает сложно установить, достигли ли слова статуса омонимов, или они еще являются лексико-семантическими вариантами одного слова. Эта трудность сказывается при составлении словарей. Таковы, например, глаголы schaffen - 'создавать, творить' и schaffen - 'работать, трудиться'. Лексически эти глаголы связаны, а грамматически уже разошлись: schaffen ('создавать') - schuf - geschaffen, а вот schaffen ('работать') - schaffte geschafft. Все это имеет разное обозначение в немецких словарях. Если в словаре стоит der Schimmel I1 и der Schimmel I2, то это слова-полисемы, а вот если имеются значки I и II, то эти слова - омонимы.

Трудность разграничения полисемии и омонимии почти всегда порождает субъективную точку зрения, прежде всего при составлении словарей. Таким трудным случаем является, например, пара слов das Werk ('завод', 'произведение', 'дело') и $\operatorname{der} \operatorname{Kopf}$ ('голова', 'заголовок газеты').

Еще в середине прошлого столетия (1957 г.) в Институте языкознания АН состоялась дискуссия по вопросам омонимии. Она преследовала прежде всего лексикографические цели - отражение омонимии в практике составления словарей. В ходе дискуссии выявились две противоположные точки зрения. Против традиционной точки зрения, которая сводилась к тому, что омонимами следует считать и слова разного происхождения, совпавшие по звучанию, и слова, которые возникли в результате распада полисемии, выступил В. И. Абаев, считавший, что омонимами являются лишь слова разные по своему происхождению, т.е. он подходил к омонимам только с исторической точки зрения и игнорировал синхронный подход, который важен для словарей современного немецкого языка [1, с. 33].

Попытка выработать критерии разграничения омонимии и полисемии в немецком языке была предпринята германистами М. Г. Арсеньевой, Т. В. Строевой и А. П. Хазанович [2]. На примере анализа нескольких многозначных существительных немецкого языка (der Zug, der Grund, die Partei и т.п.) исследователи пришли к мысли о необходимости принимать во внимание сочетаемость омонимов и многозначных слов. Так, лексико-семантический вариант ‘поезд’ реализуется в лексеме der Zug в сочетании с глаголами движения, значение 'ход' - в сочетании с оценочными прилагательными, а лексико-семантический вариант 'взвод' актуализируется в основном в сочетании с порядковыми числительными. Различная сочетаемость помогает отграничить омоним от многозначного слова. В работе М. Г. Арсеньевой с соавторами омонимы рассматривается широко. К ним относятся лексемы разных частей речи, что, конечно, спорно, поэтому многие лингвисты не разделяют эту точку зрения. М. Г. Арсеньева считает, что омонимами могут быть существительные разного рода: der Bauer - 'крестьянин' и das Bauer - 'клетка', правильные и неправильные глаголы: wiegenwog-gewogen, wiegen-wiegte-gewiegt), лексемы с разной словообразовательной потенцией, например, die Presse - 'пресс' и die Presse - 'пресса', отсюда der Pressdruck - 'давление пресса', das Presspapier - 'бумага для прессования', с одной стороны, и die Pressenkonferenz - ‘пресс-конференция', die Pressefreiheit - ‘свобода 
прессы' - с другой. Или der Stab - ‘шест’ и der Stab - 'штаб в армии', отсюда der Stabhochsprung - 'прыжок с шестом' и der Stabsarzt - ‘капитан медицинской службы'.

Вышеизложенная методика помогает выделить и омонимические глаголы. Этой методикой воспользовались и немецкие германисты Г. Хельбиг и В. Шенкель - авторы знаменитого словаря “Wörterbuch zur Valenz und Distribution deutscher Verben” [15]. Следует отметить, что при многих ценных предложениях М. Г. Арсеньевой и ее коллегам все же не удалось выработать универсальный и бесспорный критерий разграничения омонимии и полисемии. Поэтому совершенно прав Д. В. Качурин, утверждающий, что «отсутствие таких критериев пагубно сказывается в практике составления толковых словарей, в том числе и современных, ведёт к разнобою в подаче одних и тех же рядов значений (которые в одном словаре могут признаваться значениями одного слова и размещаться в одной словарной статье, а в другом - значениями разных словомонимов и подаваться в разных словарных статьях). Потому можно с достаточной уверенностью говорить об актуальности данной проблемы не только для лексикологии, но и для лексикографии» [9, с. 3].

В заключение отметим, что отечественный германист П. И. Гладкий [5] подошел к вопросу об омонимии с точки зрения семного анализа лексем. Он говорит, что der Hahn - 'петух' и der Hahn - 'кран' - омонимы, хотя у них нет ни одной общей семы. Нам представляется, что омоним со значением 'кран' возник в результате метафорического переноса наименования der Hahn со значением 'петух' на основании некоторого их сходства.

Таковы наработки отечественных германистов в области омонимии немецкого языка. Все вышесказанное позволяет сделать следующие выводы:

1) существует несколько путей возникновения омонимов в немецком языке (распад полисемии, конверсия, исторические изменения в фонетической системе немецкого языка, совпадение немецких слов и слов, заимствованных из других языков);

2) омонимы делятся на: лексические, грамматические и лексико-грамматические;

3) омонимами бывают нейтральные и стилистически окрашенные слова;

4) попытки выработать четкие критерии отнесенности слов к полисемии или омонимии до сих пор не увенчались успехами, поэтому эта тема продолжает оставаться актуальной как при обучении немецкому языку, так и при составлении словарей.

\title{
Список источников
}

1. Абаев В. И. О подаче омонимов в словаре // Вопросы языкознания. 1957. № 3. С. 31-43.

2. Арсеньева М. Г., Строева Т. В., Хазанович А. П. Многозначность и омонимия. Л.: ЛГУ, 1966. 131 с.

3. Ахманова О. С. Словарь лингвистических терминов. М.: Советская энциклопедия, 1966. 606 с.

4. Будагов Р. А. Сравнительно-семасиологические исследования. Романские языки. М.: Добросвет, 2004. 416 с.

5. Гладкий П. И. Лексическая омонимия имен существительных в современном немецком языке: автореф. дисс. ... к. филол. н. Киев, 1967.21 с.

6. Головин А. И. Омонимия как системная категория языка. Мн.: БГУ, 2007. 132 с.

7. Головня А. И. Проблема разграничения полисемии и омонимии в русском языке [Электронный ресурс]. URL: http://elib.bsu.by/handle/123456789/50202 (дата обращения: 25.06.2018).

8. Кацнельсон С. Д. Содержание слова, значение и обозначение. М.: Едиториал УРСС, 2011. 112 с.

9. Качурин Д. В. Проблема разграничения омонимии и полисемии применительно к практике составления толковых словарей: автореф. дисс. ... к. филол. н. М., 2014. 25 с.

10. Ольшанский И. Г., Гусева А. Е. Лексикология. Современный немецкий язык. М.: Академия, 2005. 416 с.

11. Реформатский А. А. Введение в языковедение. М.: Аспект Пресс, 2014. 536 с.

12. Степанова М. Д., Чернышева И. И. Лексикология современного немецкого языка. М.: Высшая школа, 1962.310 с.

13. Шумилов Н. Ф. К вопросу о разграничении полисемии и омонимии // Русский язык в школе. 1956. № 3. С. 32-35.

14. Grimm J. und W. Deutsches Wörterbuch: in 33 Bänden. München: Deutscher Taschenbuchverlag GmbH \& Co, 1984. Bd. 12. $2847 \mathrm{~S}$.

15. Helbig G., Schenkel M. Wörterbuch zur Valenz und Distribution deutscher Verben. Leipzig: VEB, 1973. 458 S.

16. Klappenbach R., Steinitz W. Wörterbuch der deutschen Gegenwartssprache: in 6 Bänden. Berlin: Akademie Verlag, 1977. Bd. 4. $3212 \mathrm{~S}$.

\section{HOMONYMS IN MODERN GERMAN: WAYS OF OCCURRENCE AND TYPOLOGICAL CHARACTERISTICS}

\author{
Shadeko Vasilii Petrovich, Ph. D. in Philology, Associate Professor \\ Nesmeyanov Aleksei Vladimirovich, Ph. D. in Philology \\ Pushkin Leningrad State University, Saint Petersburg \\ v.shadeko@gmail.com; nesmejanow@mail.ru,a.nesmeyanov@lengu.ru
}

The article gives an all-round concise overview of such a phenomenon of the German language as homonymy. Firstly, it shows how homonyms appear (disintegration of polysemy, transition of a word from one part of speech into the other, emergence of homonyms as a result of historical changes in the phonetic system of German, coincidence of German words and loan words from other languages). The authors observe the differentiation of homonyms into lexical, grammatical and lexico-grammatical ones. The paper gives the definition of full and partial homonyms. Finally, the study counterpoises neutral to stylistically coloured homonyms and points to the criteria of the delimitation of homonymy and polysemy.

Key words and phrases: meaning; form; homonymy; polysemy; homographs; homophones; etymology; borrowing; substantivization; conversion. 